\title{
Comparative prevalence level of plasmodium in freshmen (first year students) of Nnamdi Azikwe University in Awka, South-Eastern, Nigeria
}

\author{
Ibekwe, A. C., ${ }^{1}$ Okonko, I. O. ${ }^{2 \star}$, Onunkwo, A. I. ${ }^{3},{ }^{4}$ Ogun A. A, and ${ }^{5}$ Udeze A. O.
}

\begin{abstract}
${ }^{1}$ Environmental Microbiology and Biotechnology Unit, Department of Botany and Microbiology, University of Ibadan, Ibadan, Nigeria. ${ }^{2}$ Department of Virology, Faculty of Basic Medical Sciences, University of lbadan College of Medicine, University College Hospital (UCH), Ibadan, University of Ibadan, Ibadan, Nigeria. WHO Regional Reference Polio Laboratory, WHO Collaborative Centre for Arbovirus Reference and Research, WHO National Reference Centre for Influenza. HIV Reference Laboratory ${ }^{3}$ Department of Applied Microbiology and Brewing, Nnamdi Azikwe University, Awka, Nigeria.

${ }^{4}$ Department of Epidemiology, Medical Statistics and Environmental Health, Faculty of Public Health, College of Medicine, University of Ibadan, Ibadan, Nigeria

${ }^{5}$ Virology Unit, Department of Microbiology, Faculty of Sciences, University of Ilorin, Ilorin, Nigeria
\end{abstract}

E-mail:mac2finney@yahoo.com

Received 16 February 2009; received in revised form 13 April 2009; accepted 15 April 2009

\begin{abstract}
This study examines and reports the prevalence of plasmodium species between gender of freshmen (first year students) of Nnamdi Azikwe University, Akwa, South-Eastern, Nigeria. Blood film examination for malaria parasites in $200(100.0 \%)$ freshmen; $82(41.0 \%)$ males and 118 (59.0\%) females was carried out over a 6-month period. Microscopic examinations of both thick and thin blood films techniques were employed for this study. A high malaria parasite prevalence rate of $80 \%$ was noted in these subjects. Of the 200 samples examined, $160(80.0 \%)$ were Plasmodiumpositive. There was a female preponderance (F/M 2:1). A higher Plasmodium prevalence was recorded amongst females $102(86.4 \%)$ than in the males 58 (70.7\%) and there was no significant increase in malaria infection rate in any particular sex $(\mathrm{P}=0.05)$. Plasmodium falciparum was the most prevalent of all the other species. This study also shows that a good percentage of people were infested by malaria with $P$. falciparum [134 (83.8\%)] being the most prevalent species, followed by $P$. malariae [14 (8.9\%)], $P$. vivax [8 (5.0\%)] and $P$. ovale [4 (2.5\%)]. $P$. ovale was only found among the female subjects and none was found among the male subjects. The findings of this study are of a practical impact, with female subjects having the highest proportion of parasitic contamination. The higher prevalence of malaria Plasmodium found in this study could be attributed to the stagnant drainage systems in the University, which created favorable environmental conditions for the breeding of mosquitoes that act as vectors of malaria parasites and so this enhances the proliferation of the Plasmodium. It could also be attributed to the effect of climatic features on vector breeding and transmission. Wet season usually promote mosquito breeding. Also, the prevalence of $P$. falciparum could be attributed to its ability to resist attack of most drugs that are commonly in use in the study area. However, there should be a high index for the needs to take appropriate measures aimed at preventing malaria by intensifying efforts in mosquitoes eradication program through operation roll back malaria in Africa, especially in Nigeria.
\end{abstract}

Keywords: Freshmen, Malaria, mosquito eradication, Plasmodium, prevalence

\section{INTRODUCTION}

Malaria is one of the most prevalent and deadly widespread of all parasitic diseases in the world. It is mosquito-borne and one of the killer diseases of the world, currently accounting for about 300-500 million clinical cases annually and over 1.2-2.7 million deaths. Ninety $(90 \%)$ of these occur in Sub-Saharan African (WHO, 1991, 1992; Adams, 1985; Ibekwe, 2004 and Epidi et al., 2008). Malaria parasites, Plasmodium species, are generally transmitted by Anopheles species of mosquitoes. Plasmodium parasites enter the body through the saliva of the female Anopheles mosquitoes. These mosquitoes primarily inhabit the tropical and subtropical parts of the world. However, another major source of transmission is blood transfusion (MMWR, 1999 and Epidi et al., 2008). The four known species of Plasmodium which cause malaria in humans are $P$. falciparum with life cycle of 48 hours and produces malignant tertian, sub-tertian or falciparum malaria; $P$. vivax which has a 48 hours life cycle and produce benign tertian or vivax malaria; $P$. ovale which also has a life cycle of 48 hours and is the cause of ovale tertian or ovale malaria; and $P$. malariae which also has a life cycle of 72 hours and produces quartan malaria or malariae malaria. There is a marked periodicity in the rupturing of the red blood cells to release 
the merozites and metabolic wastes into the blood stream. These wastes are toxic; they result in the paroxysms of fever at regular intervals experienced by patients. These intervals differ among the species every 48 hours for $P$. vivax, $P$. falciparum and $P$. ovale, and every 72 hours for $P$. malariae. It forms good basis for distinguishing the various types of malaria (Ukoli, 1990). The life cycle of the parasite is essentially similar in all species of Plasmodia. It consists of a sexual cycle in mosquito (sporogony) and asexual cycle in humans (schizogony) (lbekwe, 2004). Organ dysfunction seen in $P$. falciparum malaria is not seen in $P$. vivax infections. Thus, severe malaria is reported with $P$. falciparum but not with $P$. vivax infection. If a patient with $P$. vivax exhibits severe malaria, the infection is presumed to be mixed. When patients have a mixed infection, $P$. vivax may lessen the effect of $P$. falciparum and cause the disease to be less severe. Luxemburger et al. (1997) observed that severe malaria is 4.2 times less common in patients with mixed $P$. falciparum and $P$. vivax infections than in those with $P$. falciparum alone.

Malaria is also rated as one of the 10 most prevalent and deadly diseases in the world. Between 300 and 500 million clinical cases occur every year with over 1.2 to 2.7 million deaths. Ninety $(90 \%)$ of these occur in SubSaharan African. The principal symptoms of malaria are fever, malaise, headache, chills and sweats but it can present as a respiratory or gastrointestinal illness. Respiratory symptoms are also frequent in uncomplicated malaria (Gozal, 1992 and Anstey et al., 2002) and acute respiratory distress syndrome has long been recognized as one of the main features of severe malaria (Brooks et al., 1968 and WHO, 2000). While mosquito bites are the most common mode of malaria transmission, one can also get malaria from blood transfusions and contaminated needles.

Many factors influence the transmission of malaria, it can exist where such conditions as the presence of suitable anopheles mosquitoes; a reservoir of malaria infection (usually the local population); suitable nonimmune or partly immune hosts and an environmental temperature of between $18{ }^{\circ} \mathrm{C}$ and $29^{\circ} \mathrm{C}$ with suitable humidity. It does not as a rule occur in regions higher than $2000 \mathrm{~m}$ above sea level. It can be prevented by avoidance of mosquito bites. Treatment of malaria is based on three major groups of drugs namely Quinine, Sulphonamides and Artemisinin. Examination of thick and thin film aids in the laboratory diagnosis of malaria.

Indeed, amongst vector borne diseases, malaria occupies a predominant position since it is probably the leading cause of death in the world despite intense national and international efforts to control it (Pickett and Hallon, 1990 and Smyth, 1994). Despite the high prevalence of disease caused by this parasite, research into its effects has lagged disproportionately (Sina, 2002). This study examines and reports the prevalence of plasmodium species between gender of freshmen (first year students) of Nnamdi Azikwe University, Akwa, Anambra State, South-Eastern, Nigeria.

\section{MATERIALS AND METHODS}

\section{Materials}

The materials employed in the study included a Leitz light microscope, EDTA (ethylene diamine tetra acetic acid) bottles, methylated spirit (methanol), cotton wool, tourniquet, syringes $(5 \mathrm{~mL})$ and needles $(21 \mathrm{~g})$ (Epidi et al., 2008).

\section{Microscopy studies}

Microscopy is the main tool for laboratory diagnosis of malaria (WHO, 1991, 1992). The thick blood film and the thin blood film methods were employed. Field's stain $A$ ( $A$ polychrome methylene blue, disodium hydrogen phosphate and potassium hydrogen phosphate) and Field's stain B (Eosin, disodium hydrogen phosphate and potassium hydrogen phosphate) was used. Thin film was carried out following the examination of thick film to identify the particular species of the Plasmodium responsible for the infection; it was stained with commercially prepared Leishman stain.

\section{Population study}

After informed consent was obtained, a total of 200 (82 males and 118 females) blood samples were collected from freshmen (first year students) of Akwa, Anambra State, South-Eastern, Nigeria. Thick blood films were prepared for each person.

\section{Method of sample collection}

The method of sample collection employed was venepuncture technique (Ibhanesebhor et al., 1996; Okocha et al., 2005 and Epidi et al., 2008). Soft tubing tourniquet was fastened to the upper arm of the patient to enable the index finger feel a suitable vein. The puncture site was then cleansed with methylated spirit (methanol) and venepuncture made with the aid of a $21 \mathrm{~g}$ needle attached to a $5 \mathrm{~mL}$ syringe. When sufficient blood had been collected, the tourniquet was released and the needle removed immediately while the blood was transferred into an EDTA bottle (Epidi et al., 2008).

\section{Laboratory analysis}

The collected blood samples were analyzed within 1-2 $\mathrm{h}$ of collection. Thick blood films were prepared according to the technique outlined by Baker et al. (2001) and Cheesebrough (2004) and described by Epidi et al. (2008). A drop of each blood sample was placed in the center of a grease-free clean glass slide. Thereafter, the reverse side of the slide was cleaned with cotton wool and kept for air-drying and staining with field's stain. The slide was held with the dried thick film side facing downward and dipped in field's stain A (eosin) for $5 \mathrm{~s}$. It was washed off gently in clean water and then dipped in field's stain B (methyl azure) for $5 \mathrm{~s}$ and washed again in clean water. 
The back of the slide was cleaned with cotton wool and kept in the draining rack to air-dry for eventual examination under the microscope.

\section{RESULTS}

The prevalence of plasmodium in 200 blood samples collected from freshmen (first year students) in this study with Plasmodium-positive and -negative slides is shown in Table 1 and Table 2. Table 1 shows the plasmodium load of the male and female subjects. Out of a total of 200 samples examined (182 males and 18 females), 160 $(80.0 \%)$ were infected with malaria parasites (Table 1$)$.

Table 1: Plasmodium load among apparently healthy subjects

\begin{tabular}{cccc}
\hline Sex & $\begin{array}{c}\text { Total } \\
\text { number } \\
\text { tested }\end{array}$ & $\begin{array}{c}\text { No. of } \\
\text { positive } \\
(\%)\end{array}$ & $\begin{array}{c}\text { No. of } \\
\text { negative } \\
(\%)\end{array}$ \\
\hline Male & 82 & $58(70.7)$ & $24(29.3)$ \\
Female & 118 & $102(86.4)$ & $16(23.6)$ \\
\hline Total & 200 & $160(80.0)$ & $40(20.0)$ \\
\hline
\end{tabular}

Amongst the males (82 samples), 58 (70.7\%) had malaria parasites, while amongst the 118 samples from females $102(86.4 \%)$ were infected. This study shows an overall plasmodium prevalence of $80 \%$ (Table 1). The distribution of the Plasmodium species found among the $160(100.0 \%)$ positive subjects is shown in Table 2, of which 134 (83.8\%) of the subjects tested positive for Plasmodium falciparum, $14(8.9 \%)$ of them had had P. malariae, $8(5.0 \%)$ of them had $P$. vivax and $4(2.5 \%)$ had $P$. ovale. No $P$. ovale was found among the male subjects (Table 2).

Table 2: Distribution of plasmodium among the subjects

\begin{tabular}{cccc}
\hline Plasmodium & No. (\%) & $\begin{array}{c}\text { No. of } \\
\text { Males } \\
(\%)\end{array}$ & $\begin{array}{c}\text { No. of } \\
\text { Females } \\
(\%)\end{array}$ \\
\hline P. falciparum & $134(83.8)$ & $48(35.8)$ & $86(64.2)$ \\
P. vivax & $8(5.0)$ & $4(50.0)$ & $4(50.0)$ \\
P. malariae & $14(8.9)$ & $6(42.9)$ & $8(57.1)$ \\
P. ovale & $4(2.5)$ & - & $4(100.0)$ \\
\hline Total & $160(100.0)$ & $58(36.3)$ & $102(63.7)$ \\
\hline
\end{tabular}

\section{DISCUSSION}

In this study, an overall plasmodium prevalence rate of $80 \%$ was noted. Also, a high malaria parasite prevalence rate of $86.4 \%$ was noted in females transfused and $70.7 \%$ in males (Table 1). This finding is higher but in agreement with Epidi et al. (2008), who reported a high malaria parasite prevalence rate of $51.5 \%$ in a similar study among transfused donor blood. The high rate of malaria prevalence in the blood samples examined was quite worrisome. This is a reflection of the high rate of asymptomatic malaria parasitaemia in endemic malaria regions (Achidi et al., 1995 and Epidi et al., 2008).

This study also showed that the most prevalent species of malaria parasite is $P$. falciparum $134(83.8 \%)$; indicating a $35.8 \%$ among the male subjects and $64.2 \%$ among female subjects. It was followed by $P$. malariae [14 $(8.9 \%)]$, P. vivax $[8(5.0 \%)]$ and $P$. ovale $[4(2.5 \%)]$. This shows that a good percentage of the freshmen were infested by malaria with $P$. falciparum being the most prevalent species. $P$. falciparum malaria epidemics were detected in 41 African sites from year 1997 through 2002 (WHO/UNICEF, 2003). A total of 125 million persons are considered at risk for malaria epidemics, with an estimated yearly death rate of 155,000 to 310,000 (Worrall et al., 2004).

The prevalence of $P$. falciparum could be attributed to its ability to resist attack of most drugs that are commonly in use in the study area. The stagnant drainage systems in the University created favourable environmental conditions for the breeding of mosquitoes that act as vectors of malaria parasites and so this enhances the proliferation of the Plasmodium species. The comparative prevalence of the plasmodium among these subjects is also attributed to the effect of climatic features on vector breeding and transmission. Wet season usually promote mosquito breeding. In this study, an overall prevalence rate of $80 \%$ was observed $(P=0.5)$ and it is not varied according sex. The most infected groups were mostly females. This is because of the high rate of female participation in the study. The reason for the much lower number of males is that males are more commercially inclined in term of monetary incentives.

This study has shown that malaria is endemic among freshmen of Nnamdi Azikwe University in Akwa. Most of the subject carried malaria parasites but were asymptomatic. Since malaria is identified as one of the deadly scourges of mankind, effective control measures must be put in place to ensure the total eradication of the mosquitoes and their breeding sites. More so, there is an urgent need to take appropriate aimed at preventing mosquito bites. These measures include selection of healthy sites for accommodation; screening windows and doors with mosquito nets; sleeping under effective mosquito treated nets; use of mosquito repellants and wearing of protective clothing. Natural mosquito habitats should also be destroyed in order to get rid of them. Empty cans could collect water and encourage breeding of mosquitoes. Regular spraying of the premises and surroundings with insecticides as well as spraying of drainage lines should also be done from time to time. However, adequate public health education should be given on regularly basis; in doing all these the operation roll back malaria will indeed be a success and a means of ensuring public health improvements in Africa. 


\section{REFERENCES}

Achidi, E. A., Perlmann, H. and Berzin, K. (1995). Asymtomatic malaria parasitaemia and seroreactivity to Plasmodium falciparum antigens in blood donors from Ibadan, South Western Nigeria. Annals of Tropical Medicine and Parasitology 86, 601-610.

Adams, M. (1985). Clinical Tropical Diseases. Prentice Hall International Inc. 8, 257-313.

Anstey, N. M., Jacups, S. P., Cain, T., Pearson, T., Ziesing, P. J., Fisher, D. A., Currie, B. J., Marks, P. J. and Maguire, G. P. (2002). Pulmonary manifestations of uncomplicated falciparum and vivax malaria: cough, small airways obstruction, impaired gas transfer, and increased pulmonary phagocytic activity. Journal of Infectious Disease 185, 13261334.

Baker, F. J., Silverton, R. E. and Pallister, C. J. (2001). Cellular pathology and Introduction to Histology. Baker's \& Silverton's Introduction to Medical Laboratory Technology. $7^{\text {th }}$ ed., Martins of Berwick, Britain. 173-243.

Brooks, M. H., Kiel, F. W., Sheehy, T. W. and Barry, K. G. (1968). Acute pulmonary edema in falciparum malaria. New England Journal of Medicine 279, 732737.

Cheesebrough, M. (2004). District laboratory practice in tropical countries. Part 2. Cambridge University Press. 357.

Epidi, T. T., Nwani, C. D. and Ugorji, N. P. (2008). Prevalence of malaria in blood donors in Abakaliki Metropolis, Nigeria. Scientific Research and Essay 3 (4), 162-164.

Gozal, D. (1992). The incidence of pulmonary manifestations during Plasmodium falciparum malaria in non-immune subjects. Tropical Medicine and Parasitology 43, 6-8.

Ibekwe, A. C. (2004). Baseline Salmonella agglutinin titres and plasmodium load investigation in apparently healthy freshmen in Nnamdi Azikwe University, Akwa. B.Sc. Thesis in the Department of Applied Microbiology and Brewing, Faculty of Natural Sciences, Nnamdi Azikwe University, Akwa, Nigeria.

Ibhanesebhor, S. E., Otobo, C. S. and Ladipo, O. A. (1996). Prevalence of malaria parasitaemia in transfused blood donor in Benin-City, Nigeria. Annals of Tropical Paediatrics 16, 93-95.

Luxemburger, C., Ricci, F., Raimond, D., Bathet, S. and White, N. J. (1997). The epidemiology of severe malaria in an area of low transmission in Thailand. Transaction Royal Society of Tropical Medicine and Hygiene 91, 256-262.

Morbidity and mortality weekly report (MMWR). (1999). Malaria. MMWR 48 (12), 253-256.

Okocha, C. E. C., Ibeh, C. C., Ele, P. U. and Ibeh, N. C. (2005). The prevalence of malaria parasitaeia in blood donors in a Nigerian Teaching Hospital. Journal of Vector Borne Diseases 142, 21-24.
Pickett, G. and Hallon, J. J. (1990). Public health administration and practice. Times Mirror/Mosby College publishing. 583.

Sina, B. (2002). Focus on Plasmodium vivax. Trends in Parasitology 18, 287-289.

Smyth, J. D. (1994). Animal parasitology. Cambridge University press. 549.

Ukoli, F. M. A. (1990). Introduction to parasitology in tropical Africa. Textflow Ltd., Ibadan. 252-266.

World Health Organization (WHO, 1991). Malaria. Bulletin of the World Health Organization 4-14.

World Health Organization (WHO, 1992). Expert Committee on Malaria. 19th report. WHO technical report series No. 735. Geneva.

World Health Organization (WHO, 2000). Severe falciparum malaria. Communicable Disease Cluster. Transaction Royal Society of Tropical Medicine and Hygiene 94, 190.

World Health Organization/UNICEF. (2003). The Africa malaria report 2003. Geneva: WHO/Roll Back Malaria;2003. Net information. http://www.unicef.org/publications/index_7936.html

Worrall, E., Rietveld, A. and Delacollette, C. (2004). The burden of malaria epidemics and costeffectiveness of interventions in epidemic situations in Africa. American Journal of Tropical Medicine and Hygiene 71, 136-140. 